skin is removed immediately after the eyes have cleared again, the snake of ten dies. ${ }^{2}$ The situation is made more complex by evidence that "many species seek water to soak themselves at this time, since they lose a good deal of body liquid along with the old skin [Carr, 1963, p. 102]."

\section{REFERENCES}

BITTERMAN, M. B. An instrumental technique for the turtle. Journal of the Experimental Analysis of Behavior, 1964, 7, 189-190.

CARR, A. The reptiles. New York: Time, Inc., 1963.

CRAWFORD, F. T., \& BARTLETT, C. W. Runway behavior of the gray rat snake with food and water reinforcement. Psychonomic Science, 1966, 4, 99-100.

CRAWFORD, F. T., \& HOLMES, C. E. Escape conditioning in snakes employing vibratory stimulation. Psychonomic Science, 1966, 4, 125-126.
IERSTER, C. B.. \& SKINNER, B. F. Schedules of reinforcement. Ncw York: Appleton-Century-Crofts, 1957.

KELLOGG, W. N., \& POMEROY, W. B. Maze learning in water snakes. Journal of Comparative Psychology, 1936, 21, 275-295.

SKINNER, B. F. The behavior of organisms New York: Appleton-Century-Crofts, 1938.

SKINNER, B. F. Science and human behavior. New York: Macmillan, 1953.

TAKEMOSA, T., \& NAKAMURA, K. Hebì mochieto hitotsuno gakushi jikken (A learning experiment with snakes). Kyoiku Shinri Kerkyu, 1935, 10, 575-581.

WOLFLE, D. L., \& BROWN, C. S. A learning experiment with snakes. Copeia, 1940, 2, 134.

\section{NOTES}

1. The author gratefully acknowledges the many helpful suggestions of Dr. Daniel B. Cnuse in this work.

2. Haast, W. Personal communication, 1966.

\title{
Variations in fluid intake following shifts between water and saccharin solution
}

VINCENT DILOLLO and PETER N. MEYER, The University of Western Australia, Nedlands, W.A. 6009, Australia

Four groups of 12 nondeprived rats each were presented with an additional bottle (B2) in the home cage for $1 \mathrm{~h}$ each day. Intake from $B 2$ was measured during preshift (10 days), Shift 1 (5 days), and Shift 2 (5 days). The bottle, B2, contained either tap water (W) or .25\% saccharin solution (S) for each group as follows: $W W W, S S S$, SWS, and WSW, where the three letters refer to the contents of $B 2$ during preshift, Shift 1, and Shift 2 , respectively. Intake from $B 2$ was uniformly greater when it contained saccharin solution, but neither positive nor negative contrast effects were obtained at any stage of the experiment.

A negative contrast effect is demonstrated if, following a decrement in the amount of reward, performance drops below the level set by a control group always maintained at the lower amount. Conversely, a positive contrast effect is obtained if, following an increment in reward, performance overshoots the appropriate control level. Both phenomena were originally demonstrated by Crespi (1942), who, instead of nonshifted controls, used extrapolated preshift values as the basis for postshift comparisons. The omission of control groups led to the objection that a positive contrast effect may represent an increment in performance attributable to the effect of additional acquisition trials following the shift (Spence, 1956). The objection was supported by subsequent experimentation that provided ample confirmation of negative, but not of positive, contrast effects under appropriate control conditions (e.g., Schrier, 1967).

A positive contrast effect in the intake of saccharin solution has been reported recently by Gandelman \& Trowill (1969). The design involved a group of rats maintained on ad lib food and water throughout. A second bottle, presented to each $S$ for $1 \mathrm{~h}$ on each day, contained saccharin solution for the first 13 days, water for the next 3 , and again saccharin solution for the final 7 days. The mean amount of saccharin intake during the third stage exceeded that of the first stage, and this was taken as evidence of positive contrast. Clearly, since a control group always maintained on saccharin solution was not run, intake differences between first and third stages could represent the incremental effect of additional trials rather than a positive contrast effect.

The study reported here investigated variations in fluid intake following shifts to both water and saccharin solution in relation to the intake level of nonshifted controls.

\section{SUBJECTS}

The Ss were 48 male albino rats from the colony maintained at the University of Western Australia. They were approximately 120 days old at the beginning of the experiment and were housed individually. All Ss were maintained on ad lib food and water throughout the experiment.

PROCEDURE

All testing took place in the home cages. The part of the experimental procedure common to all groups consisted in the presentation of a second bottle (B2) for $1 \mathrm{~h}$ each day in addition to the maintenance water bottle (B1) always present in the cage. In every case, B2 was fitted with a leakproof metal spout manufactured by Atco Mfg. Co., Napa, California. The orifice of this type of spout is sealed by two metal balls, one behind the other, that make a distinct clicking sound while the $S$ is licking. The maintenance bottles were fitted with ordinary metal spouts that allowed some leakage and thus obviated accurate measurement of fluid intake. The contents of B2 were either $0.25 \%(w / v)$ saccharin solution (sodium saccharin and plain tap water) or just plain tap water, depending on the experimental condition. The experiment was conducted in three stages: preshift (10 days), Shift 1 (5 days), and Shift 2 ( 5 days). The 48 Ss were assigned randomly to the following four groups of $12 \mathrm{Ss}$ each: Group WWW, Group WSW, Group SSS, and Group SWS. The three letters in each group designation indicate whether B2 contained water (W) or saccharin solution (S) during preshift, Shift 1, and Shift 2, respectively.

\section{RESULTS}

The amount of fluid intake from B2 was measured after each daily session, with a resolution of $0.25 \mathrm{ml}$. The mean B2 intake scores for each group on each day of the experiment are shown in Fig. 1.

By the second day, all Ss drank from B2. During preshift there was a clear separation between the groups receiving saccharin solution and those receiving plain water. On the 1st day of Shift 1, there was a pronounced decrement in the mean intake of Group SWS but only a small, though significant, increment in Group WSW $[F(1,11)=6.98, p<.05]$. During Shift 1 , the mean intake of Group WSW increased markedly and that of Group SWS showed a gradual decrement, but neither group reached the level of the respective controls. Over the 5 days of Shift 1, Group SWS drank more from $B 2$ than did the WWW controls $[F(1,22)=10.63, p<.005]$.

On the 1st day of Shift 2, Group WSW showed a sudden drop in mean intake, and Group SWS showed a sudden increment 


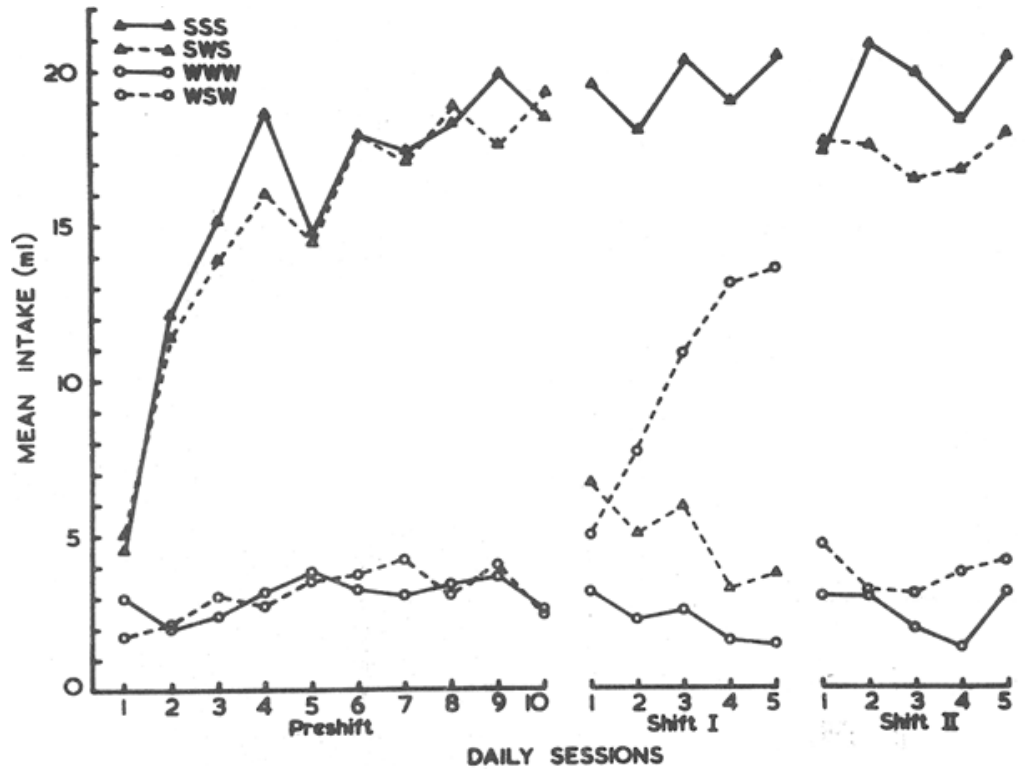

that differed markedly from the slow increment of Group WSW in Shift 1. Over the 5 days of Shift 2, Group WSW drank more from $B 2$ than did the WWW controls $[F(1,22)=5.84, p<.05]$, but, in spite of the graphical suggestion (Fig. 1), the mean intakes of Groups SWS and SSS did not differ reliably $[F(1,22)<1]$.

\section{DISCUSSION}

No evidence of contrast effects was obtained at any stage of the experiment. On the contrary, during both shift stages, the shifted groups did not reach the levels set by the relevant controls. The increased intake reported by Gandelman \& Trowill (1969), when the Ss were returned to saccharin solution after a period on plain water, must thus be regarded as representing effects other than positive contrast, notably the effect of additional trials. It is also evident that the relatively greater intake rate reported by Gandelman and Trowill during the postshift stage was at least partly determined by an unexplained intake decrement during the second half of the preshift period (Gandelman \& Trowill, 1969, Fig. 1). A similar decrement was not observed in the present study.

Ample and rapid intake decrements, suggestive of motivational changes, were obtained following shifts to water in both postshift stages. Intake increments after shifts to saccharin, however, were gradual in Shift 1 and rapid in Shift 2. It is notable that the rate of intake increment of Group WSW during Shift 1 is not unlike that of Groups SWS and SSS during the first part of preshift. Although it seems clear that a learning factor is involved in the growth of daily intake of saccharin solution, the nature of the habit is not
Fig. 1. Mean fluid intake from $B 2$ for each group on each day of the experiment.

immediately obvious. It is possible that the large intake during the experimental sessions (almost 7\% of the S's mean body weight) was paralleled by a corresponding reduction in water intake during the intervening $23 \mathrm{~h}$ periods. The gradual increments in daily saccharin intake exhibited by Groups SSS, SWS, and WSW after the first presentation of saccharin solution could thus represent the development of a drinking schedule set to maximize the volume of saccharin intake. Under these circumstances, it should be true that water intake from B1 during the $23 \mathrm{~h}$ between two test periods should be greater for, say, Group WWW than for Group SSS. Since B1 was not fitted with a leakproof spout, the required measurement could not be taken in the present study.

As noted earlier, shifts from saccharin to water yielded intake levels that were reliably greater than the control level. A simple account for this result can be given in terms of conditioned reinforcement: Through its association with saccharin solution, the clicking sound of B2 became a conditioned reinforcer and, after a shift to water, it maintained a greater amount of licking than in the nonshifted water controls.

\section{REFERENCES}

CRESPI, L. Quantitative variation of incentive and performance in the white rat. American Journal of Psychology, 1942, 15, 467-517.

GANDELMAN, R., \& TROWILL, J. A. Effects of reinforcement shifts upon subsequent saccharin consumption. Psychonomic Science, $1969,15,25$.

SCHRIER, A. M. Effects of an upward shift in amount of reinforcer on runway performance of rats. Journal of Comparative \& Physiological Psychology, 1967, 64, 490-492.

SPENCE, $\mathrm{K}$. W. Behavior theory and conditioning. New Haven: Yale University Press, 1956. 